\title{
FAKE PICTURES. FALSIFICACIÓN DE IMÁGENES CIENTIIFICAS Y AVANCES ACTUALES EN EL ANÁLISIS FORENSE. ANÁLISIS DE CASOS.
}

\author{
Dr. Francisco López-Cantos \\ Universitat Jaume I, Castellón, España \\ flopez@uji.es \\ ORCID iD: https://orcid.org/0000-0002-6674-4825
}

Mg. Alejandro Maestre Gasteazi

Miembro de la Asociación Española de Imagen Científica y Forense, Murcia, España alejandro.maestre@imagencientifica.es

Recibido el 27 de noviembre de 2018

Aceptado el 1 de marzo de 2019

\section{Resumen}

En esta investigación se hace un recorrido por el fraude científico haciendo especial hincapié en el impacto que la divulgación de imágenes científicas falsas ha tenido históricamente para, posteriormente, realizar una aproximación a los últimos avances en técnicas de análisis y detección de imágenes falsas utilizando como ejemplo dos estudios de caso. Se concluye que la utilización de técnicas de análisis forense y la peritación de imágenes contribuye a limitar el impacto actual que la pandemia de fake news/fake pictures está teniendo en todos los ámbitos comunicativos en general y, en lo que nos ocupa en este trabajo, está adquiriendo cada vez una mayor relevancia en la actividad investigadora y la comunicación pública de la ciencia.

Palabras clave: Fake Pictures, Fake News, Fraude Científico, Imagen Científica, Investigación Científica, Cultura Visual. 


\title{
FAKE PICTURES. FALSIFICATION OF SCIENTIFIC IMAGES AND CURRENT ADVANCES IN FORENSIC ANALYSIS. CASE ANALYSIS.
}

\begin{abstract}
This research is a tour through scientific fraud with special emphasis on the impact that the dissemination of false scientific images has historically had, in order to subsequently make an approximation to the latest advances in techniques of analysis and detection of false images, using two case studies as an example. It is concluded that the use of forensic analysis techniques and image expertise contributes to limiting the current impact that the fake news/fake pictures pandemic is having on all areas of communication in general and, as far as we are concerned in this paper, is becoming increasingly relevant in the research activity and public communication of science.

Keywords: Fake Pictures, Fake News, Scientific Fraud, Scientific Image, Scientific Research, Visual Culture.

\section{Cómo citar este artículo:}

López-Cantos, F., Maestre, A., "Fake Pictures. Falsificación De Imágenes Científicas Y Avances Actuales En El Análisis Forense. Análisis De Casos.", en Perspectivas de la Comunicación, Vol. 12, Nº 1. pp. 209-226.
\end{abstract}


Introducción

D

esde la invención del telescopio hacia 1609 por Galileo, y su cuidada edición de dibujos detallados de la Luna y las fases de Venus, Siderius nuncius (el mensajero de las estrellas), en la que resumía sus observaciones astronómicas, se impulsó de manera consciente el perfeccionamiento de la instrumentación científica para hacer visibles los territorios de la Naturaleza que permanecían inexplorados. La ilustración científica se convirtió en una herramienta habitual para el registro de los resultados experimentales y la descripción de los fenómenos objeto de análisis hasta el punto de que no era raro que los propios investigadores desarrollaran sobremanera sus talentos artísticos para poder reflejar en sus dibujos la síntesis de sus trabajos, en algunas ocasiones en exceso, como hiciera Hooke en su enciclopédica obra Micrographia, en la que sin pudor alguno dibujó y mitificó algunos insectos, sobre todo arácnidos, a una escala a la que era imposible verlos con los microscopios de la época (Gest, 2009).

Las técnicas fotográficas, se incorporaron al trabajo científico un siglo y medio después y, aunque durante algún tiempo convivieron las ilustraciones científicas junto con las reproducciones fotográficas, muy pronto aquéllas se consideraron poco más que una extravagancia y fueron rápidamente sustituidas por los procedimientos mecánicos inherentes a la nueva tecnología, que encajaba a la perfección con las aspiraciones de objetividad para cierto positivismo científico que se vio de nuevo revitalizado. Al uso de la nueva técnica pronto empezaron a sumarse multitud de científicos-fotógrafos que utilizaban el registro fotográfico como herramienta imprescindible en sus investigaciones y se inauguró lo que ha venido denominándose era de la "objetividad mecánica" (Daston y Galison, 2007) en la que la fotografía no sólo servía para difundir los resultados de la investigación o apoyar la reflexión y la generación de conocimiento sino que también se constituyó pronto en sí misma en un objeto epistémico autónomo con naturaleza probatoria (Lopez-Cantos, 2010, 2015). El impresionante desarrollo actual de nuevas técnicas de captación y de registro digital de imágenes científicas no sólo se ha multiplicado con los avances en muy diversas áreas de conocimiento, sino que el análisis de la representación del conocimiento se ha convertido en un privilegiado objeto de estudio en tanto que se ha convertido en un elemento definitorio de nuestra cultura contemporánea (Lopez-Cantos, 2016, 2017).

La complejidad de la sociedad actual, que con acierto se ha denominado sociedad del riesgo (Beck, 1992), es mucho mayor que en aquellos tiempos en que la divulgación de la famosa xilografía de Durero que representaba un exótico rinoceronte blanco al que nunca vio y dibujó a partir de algunas notas escritas y bocetos que le hicieron llegar. Y, aunque parece ser que no había ninguna intención expresa por parte del pintor de falsificar los datos, lo cierto es que el rinoceronte se acabó por convertir en un icono cultural de la época que, a pesar de no ser más que una mera recreación, daba fe pública de su existencia. En un entorno digital y multimedia en red como el nuestro en que las comunicaciones se producen con gran rapidez y a escala global no resulta sorprendente que se hayan disparado todas las alarmas ante la masiva propagación de contenidos fraudulentos. Como resultado de la extraordinaria proliferación en la sociedad-red actual de rumores (hoax) y noticias falsas (fake news) se están poniendo en marcha multitud de estudios e iniciativas utilizando las herramientas tecnológicas disponibles en la actualidad para estudiar el fenómeno y limitar el impacto social (Balmas, 2014; Huckle \& White, 2017; 
Vargo, Guo \& Amazeen, 2018; Tandoc, Lim \& Ling, 2018; Lazer et al., 2018) de un fenómeno que está poniendo en cuestión los fundamentos de nuestras actuales sociedades, para algunos ya en tránsito hacia una nueva era denominada de la post-verdad (Keyes, 2004; Sismondo, 2017; Mihalidis \& Viotty, 2017; D'Ancona, 2017).

En el ámbito científico el fraude y la falsificación no es, como decimos, un fenómeno novedoso, pero las preocupaciones ante tal fenómeno se están incrementando notablemente en la actualidad tal como recientemente se expresa en las editoriales de prestigiosas publicaciones como Nature o The Lancet (Higgins, 2016; Marmot, 2017), y en el complejo entorno contemporáneo en que se desarrolla la actividad investigadora, el estudio de la falsificación de imágenes (fake pictures) adquiere una urgente relevancia entre la proliferación de contenidos multimedia que se distribuyen con rapidez y cuya veracidad resulta cada vez más difícil de probar.

En este artículo, hacemos una revisión del estado de la investigación y las herramientas de que se dispone en la actualidad para el análisis forense de imágenes que entendemos puede ser de mucha utilidad para el estudio de las imágenes científicas falsas, aunque su ámbito de aplicación es extensivo a cualquier fakepicture, así como lo es el uso de las técnicas de análisis forense a otros ámbitos, entre ellos la práctica jurídica.

\section{El fraude científico.}

Entre las conductas inapropiadas en la práctica investigadora, según la National Science Foundation (NSF, 2006) se pueden distinguir diversos grados de manipulación para obtener resultados desde su fabricación y registro; la falsificación realizada como resultado de la manipulación de los materiales, los procesos o los equipos de investigación cambiando u omitiendo datos o los resultados obtenidos; y el plagio en tanto apropiación de las ideas, procesos o resultados de otras personas sin indicar sus autores. En algunos casos esta conducta es cuando menos reprobable ya que puede ser resultado del desconocimiento o la imprudencia, pero las más de las veces es una actitud intencional ${ }^{1} y_{\text {, }}$ por lo tanto, punible; su prevalencia entre la comunidad científica está siendo objeto prioritario de estudio y movilizando ingentes recursos para detectar el fraude (Kroll, 2011).

Los casos de fraude científico, como decíamos, tienen una larga historia, que hay quien remonta a las investigaciones astronómicas de Ptolomeo o el propio Galileo (Broad \& Wade, 1982). Y, aunque tradicionalmente se ha considerado la actividad científica como genuina y honesta, y lo es en la mayoría de los casos, el descubrimiento de fraudes notorios muestra la fragilidad del conocimiento científico y la facilidad para el fraude. Por ejemplo, el caso del supuesto descubrimiento del cráneo del hombre de Piltdown a principio del siglo $X X$ o los estudios inventados sobre la inteligencia heredada en gemelos del psicólogo Cyril Burt, ambos declarados falsos en 1954 y 1974 respectivamente tras décadas en que su validez era incuestionable. También se conoce el caso del brillante cardiólogo de Harvard

\footnotetext{
${ }^{1}$ El plagio es muy común y puede ser el resultado de la mera negligencia bibliográfica o de una más intencionada "citation amnesia" o "disregard syndrome", tanto como del uso de datos de otras investigaciones que se presentan como novedosos o como de la atribución de la investigación a personas que no han participado en ella, así como el autoplagio publicando la misma investigación con mínimos cambios en diversas revistas o lenguas. La consecuencia a medio plazo de este tipo de conducta deriva, de un lado, en el empobrecimiento del conocimiento y, de otro, en lo que Merton (1968) denominó Efecto Matthew, según el cual el efecto de la acumulación en algunas personas da lugar a significativas ventajas en su ámbito de actividad, es decir, el investigador citado es cada vez más citado, o quien aparece como autor en trabajos no propios de sus colaboradores acaba por ser considerado un investigador prestigioso y de excelencia por la mera acumulación derivada de este efecto.
} 
que publicaba alrededor de 100 artículos por año con datos inventados o manipulados (Goodstein, 1991). Otros casos clásicos de fraude científicos han pasado a la posteridad, algunos de ellos irrisorios, como el de inmunólogo americano William Summerlin que intentó hacer pasar un parche pintado con rotulador negro por un exitoso injerto de pieles entre dos especies de ratones blancos y negros.

El análisis de distintos estudios recientes preguntan a los propios científicos sobre el fraude en sus investigaciones. Los resultados del meta-análisis permiten calcular que alrededor del $2 \%$ de ellos han cometido algún fraude de manera consciente a lo largo de su carrera (Fanelli, 2009), pero sin embargo, y de acuerdo con RetractionWatch.com, en 2015 sólo fueron retirados 684 artículos de un total de 800.000 . Los resultados del análisis automatizado utilizando software específico son muy reveladores $y$, por ejemplo, utilizando un ingenioso software recientemente desarrollado por el joven científico holandés Chris Hartgerink en colaboración con Michel Nuijten para detectar los errores estadísticos Ilamado Stat-check, han concluido que de un total de alrededor de 16.000 artículos que usaban estadísticas sobre los 30.000 artículos publicados en el área de psicología analizados, al menos la mitad contenía errores estadísticos (Nuitjen et al., 2016). En otra investigación realizada a partir del análisis textual automatizado, de un total de 253 artículos del área de biomedicina que en el período entre 1973 y 2013 habían tenido que retirarse una vez publicados por haber sido detectados como falsos, se ha creado el que sus autores han denominado "obfuscation index," para evaluar la aparición de "causal terms, abstract language, jargon, positive emotion terms and a standardized ease of reading score", y se ha encontrado que existen significativas analogías en la forma de mentir entre los científicos cuando incurren en este tipo de conductas fraudulentas (Markowitz \& Hancock, 2016).

Algunos de los últimos casos desvelados sobre el trabajo fraudulento de científicos con multitud de artículos publicados han acabado de forma dramática, como el de los japoneses Sato y Sasai. Después de una ardua investigación se descubrió que los resultados obtenidos por Sato en sus estudios clínicos que fueron publicados en más de 200 artículos, muchos de ellos sobre cómo reducir los riesgos de fractura ósea pero también sobre el Alzheimer o el Parkinson entre otros, habían sido totalmente fabricados. Yoshiki Sasai, eminente científico experto en células madre, al ser descubierto su fraude en la fabricación de datos acabó por suicidarse, probablemente como hiciera Sato, quizá como consecuencia del gran deshonor que supondría para una cultura como la japonesa haber sido descubierto, una cultura en la que sus científicos paradójicamente ocupan los primeros lugares en número de artículos retirados de las revistas (Kupferschmidt, 2018).

En cualquiera caso, más allá de las consecuencias legales que el fraude científico pueda tener para sus autores y su retirada de la publicación, las consecuencias para la comunidad científica y para la sociedad son de gran alcance. Según los cálculos de 2012 de la empresa Ithenticate, que desarrolla herramientas de autenticación y verificación para multitud de agencias gubernamentales de Estados Unidos, entre ellas la NSF, el fraude abarca desde el plagio en todas sus formas hasta la falsificación de datos en las solicitudes de proyectos o de resultados en los informes financieros de los grupos de investigación; el coste de las malas prácticas científicas rondaría los 100 billones de dólares anuales (Ithenticate, 2012). Todavía no hay metaanálisis que incluyan el impacto global en la investigación, pero, sin duda, la magnitud del fraude científico provoca grandes pérdidas a los presupuestos gubernamentales y a la economía de los sistemas públicos y privados y, en definitiva, a toda 
la sociedad en tanto responsables y beneficiarios de la financiación de los proyectos de investigación.

\section{La falsificación de imágenes científicas.}

Al igual que, como decíamos, se ha popularizado el fenómeno fake news y se están redoblando los esfuerzos para analizar su impacto como la nueva epidemia contemporánea (Kucharski, 2016), son muy conocidos algunos de los casos de falsificación de imágenes que se han producido a lo largo de la historia, sobre todo en las fotografías de políticos como Stalin, Mao, Castro o el mismísimo Abraham Lincoln, cuya conocida imagen se elaboró tomando prestado el cuerpo de otra persona para dar al presidente un aspecto más heroico. ${ }^{2}$

En la actualidad la falsificación de fotografías es una práctica común en todos los ámbitos y la tecnología digital permite hacer que la manipulación pase cada vez más desapercibida. En un estudio que se ha hecho desde la Universidad de Warwick con un total de 700 personas, la tasa de identificación de imágenes falsas que los participantes son capaces de detectar a simple vista es de aproximadamente entre el 30 y el 40 por ciento de las que han sido manipuladas (Nightingale, Wade \& Watson, 2017). Sin embargo, el análisis detallado de las imágenes puede permitir la detección de manipulaciones y montajes de imágenes de manera sencilla a partir de, por ejemplo, el análisis de la dirección y reflexión de la luz o de la posición de los ojos, incluso del lugar de la pupila en que se refleja la luz o, con algo más de conocimiento técnico, hacer búsquedas inversas para detectar copias. A otro nivel más alto de dificultad técnica se pueden analizar los datos de captura o utilizar software de análisis para detectar transformaciones en la estructura de los datos digitales de registro.

El fraude en las imágenes científicas puede ser mucho más difícil de detectar, aunque en algunos casos es muy notorio, así se desprende del análisis realizado por el laboratorio Shigeaki Kato Laboratory de la Universidad de Tokio de las imágenes contenidas en un artículo que había sido publicado en 2009 en Nature y considerado válido durante varios años por la comunidad investigadora; en dicho artículo se encontraron nada menos que 20 fraudes en las imágenes. Otras investigaciones sobre el uso de imágenes en las publicaciones en el área de biomedicina sobre la base de datos PubMed han encontrado que en algunas áreas específicas de investigación, como la oncología, el 25\% del total de artículos publicados contenía imágenes resultantes de la experimentación con geles que eran falsas (Oksvold, 2015); y que de todos los artículos analizados sobre una muestra de 1364 seleccionados aleatoriamente de 451 revistas de PubMed, alrededor del 6\% contenían imágenes claramente fraudulentas (Bucci, 1018), y eso sólo analizando una limitada gama de manipulaciones posibles en la imagen.

El número de casos de conductas fraudulentas en el que la validez de las imágenes científicas es cuestionada se ha venido incrementando a lo largo de las dos últimas décadas y ha pasado de suponer sólo el 2,5\% en un estudio realizado para los años 1989-1999 a un preocupante $68 \%$ del total de los casos de fraude en uno posterior para los años 2007-2008 (Krueger, 2009; Parrish and Noonan, 2009; Pearson, 2005). Consecuencia de ello, de una década a esta parte y siguiendo la tradición que ya era práctica habitual en la Royal Society desde sus inicios de consensuar la validez de las imágenes (Lopez-Cantos, 2017a), algunas de las publicaciones científicas más prestigiosas, como Nature (Nature, 2006), han venido

\footnotetext{
2 Se puede consultar en https://www.dailymail.co.uk/news/article-210710g/lconic-Abraham-Lincoln-portraitrevealed-TWO-pictures-stitched-together.html
} 
elaborando guías para los autores y protocolos éticos para evitar la alteración de las imágenes que se publican, y cada vez son más los trabajos que se ocupan de determinar las buenas prácticas en la producción de imágenes científicas, por ejemplo en Cromey (2013). El incremento de las falsificaciones, recogiendo las conclusiones del análisis realizado por Emma Frow sobre las políticas editoriales de las mayores revistas científicas, va más allá de la mera detección del fraude, la intención normativa de las revistas científicas está poniendo en cuestión la integridad de la labor científica: "the current concerns of journal editors revolve less around determining the so-called truth or falsity of digital images and are more about setting norms for image production as a means of safeguarding trust in the published image." (Frow, 2012: 29). Conscientes de la potencia e impacto de la tecnología digital para el tratamiento de imágenes en la elaboración de imágenes científicas y dada la complejidad actual para un análisis efectivo, se está recurriendo a la contratación de expertos en imagen forense para la revisión de su validez antes de su publicación (Pearson, 2005; Couzin, 2006).

El análisis forense de imágenes ha dado notables frutos y con las nuevas técnicas digitales aún tiene mucho recorrido, como por ejemplo el realizado con la famosa fotografía de Lee Harvey Oswald que desde hace décadas ha alimentado multitud de teorías conspirativas; tras un pormenorizado análisis forense fueron desmentidas por Farid (2009). ${ }^{3}$ Más allá del análisis clásico, la actual urgencia de limitar la proliferación de imágenes falsas está obligando a que se movilicen ingentes cantidades de recursos financieros y técnicos, como por ejemplo los agrupados en torno al programa estadounidense Medifor en el seno de Darpa (Defense Advance Research Projects Agency) o en torno al HEADT Centre (Humboldt-Elsevier Advanced Data and Text Centre) creado en 2016 con base en Berlín, en el desarrollo de soluciones que permitan identificar falsificaciones cuya complejidad hace cada vez más difícil su detección, también y como resultado, de las propias herramientas tecnológicas que se utilizan para ocultar el fraude.

La verificación de la autenticidad de las imágenes digitales, en definitiva, se está convirtiendo en una necesidad en multitud de ámbitos, y el análisis forense de imágenes, en este sentido, se convierte en la actualidad en una práctica pericial extensiva a cualquier actividad susceptible de tratamiento jurídico, como también lo es la actividad científica y, como consecuencia de ello, se están desarrollando soluciones tecnológicas que van mucho más allá de los análisis clásicos de imágenes.

\section{El análisis forense de imágenes y la práctica pericial.}

En la actualidad el análisis forense de imágenes digitales constituye uno de los mayores retos técnicos de la peritación tecnológica e informática. La ausencia de protocolos de análisis de imágenes digitales, la escasez e ineficacia de las herramientas de software y el desconocimiento generalizado de los principios científicos y tecnológicos de la formación de la imagen digital son algunos de los problemas que todo experto en análisis forense de imágenes debe resolver.

El proceso de obtención de imágenes se desarrolla en una serie de fases sucesivas que van desde el momento en que la luz interacciona con la escena fotografiada hasta que, tras ser dirigida por un sistema óptico al sensor del dispositivo de captura y ser codificada en un

\footnotetext{
3 Hany Farid es uno de los mayores expertos mundiales en análisis forense de imágenes y colabora en el proyecto Medifor de Darpa, su exitoso libro Photo Forensics de 2016 publicado en MIT Press tendrá una reedición prevista a lo largo del año 2019.
} 
conjunto estructurado de datos binarios, se acaba registrando en un archivo digital con un formato específico, por ejemplo los populares JPEG, TIFF, BMP, etc. o, si se trata de imagen en movimiento en formatos tales como AVI o QuickTime, entre los más conocidos. En cada una de las sucesivas fases del proceso fotográfico se producen intervenciones específicas propias del sistema de obtención de imágenes utilizadas que permiten caracterizar la fotografía e, incluso, determinar su origen y el dispositivo con que se registró esa imagen particular $y$, si fuera necesario, certificar su autenticidad o, lo que es lo mismo, verificar que la imagen no ha sido manipulada.

La obtención de imágenes científicas resulta de especial complejidad debido a la utilización de sistemas tecnológicos que se sitúan en la frontera del conocimiento, pues en muchos casos se construyen ad hoc y requieren ingentes recursos económicos y la participación de toda la comunidad científica internacional. Su correcto funcionamiento acaba siendo el resultado del consenso entre una amplia comunidad de investigadores, pero, incluso con la máxima observancia de los sistemas y procesos empleados, la validez de los resultados e imágenes obtenidas pueden estar sujetas a discusión o requerir una profunda revisión de todo el sistema tecnológico como ocurrió, por ejemplo, cuando se puso en órbita el telescopio Hubble y la propia NASA detectó que padecía miopía (Allen, 1990).

En general, entre la comunidad científica se acaba por contrastar y validar los resultados obtenidos en cualquier investigación, con mayor o menor discusión o a veces incluso obligando a los autores de determinada investigación a retirar su trabajo o retractarse, como ya hemos comentado. Y ese consenso se da de esta manera en relación a los datos que ha ido enviando el telescopio espacial a lo largo de los casi 30 años que lleva en funcionamiento $y$, resultado de ello, en el imaginario colectivo se han instalado las impactantes imágenes coloreadas de los confines de la galaxia que ha popularizado la propia NASA y los medios de comunicación. Sin embargo, todavía hoy y sin duda fruto del desconocimiento absoluto de cómo funciona el proceso de investigación científica, resuenan libremente por las redes los ecos de teorías conspirativas en relación con otro hito de la exploración espacial como el legendario alunizaje del Apolo XI en 1969 pretendiendo sostener que se trataba de una imagen falsa, cuya autenticidad mostraremos más abajo junto a otro ejemplo, en este segundo caso sí de imagen falsa.

Como venimos diciendo, durante todo el proceso fotográfico se interviene sobre la imagen original y se deja rastro y aunque los falsificadores puedan borrar los archivos de metadatos registrados junto a la imagen ${ }^{4}$ un análisis pericial en profundidad podría establecer si una determinada imagen se capturó con una cámara particular y, de esta manera, identificar su autoría. Los falsificadores, sin embargo, suelen preferir operar sobre el archivo de imagen digital final utilizando programas de manipulación informática que disponen de herramientas de sencillo uso que, como el popular Photoshop, permiten multitud de operaciones sobre la imagen que van desde el simple reencuadre o el tratamiento sobre el contraste o el color, hasta la generación de clonados o la realización de fotomontajes más o menos complejos. Pero el rastro de su actuación fraudulenta, igualmente, puede ser analizado para verificar si la imagen ha sido modificada.

\footnotetext{
4 En un archivo de imagen se registran también datos sobre cómo y con qué equipo se realizó la captura, e incluso datos de localización, en un formato particular denominado EXIF que no sólo se puede consultar sino que también se puede manipular.
} 
Las técnicas para determinar si una imagen es fraudulenta están dirigidas, de una parte, a determinar la integridad lógica y los metadatos del archivo digital de imagen (Aguado \& Antona, 2012) y, de otra, a detectar posibles manipulaciones como fotomontajes, reencuadres, eliminaciones parciales o clonados (Conotter, Boato \& Farid, 2010; Mishra \& Adhikary, 2014). Veamos dos ejemplos.

\section{Ejemplo 1. La llegada a la Luna y las teorías conspirativas.}

Nuestro sistema de visión es fácil de engañar y un fotomontaje realizado por un experto en postproducción digital podría confundir sin mucha dificultad a un espectador no experimentado. Sin embargo, pocos expertos en tratamiento digital son capaces de realizar un fotomontaje capaz de respetar por completo el comportamiento de la luz en una escena. Es por ello que una de las técnicas más efectivas consiste en el análisis de la integridad de luces y sombras buscando incoherencias en la proyección de sombras, detectando así el origen de cada fuente de iluminación a partir del conocimiento matemático del comportamiento de la luz al incidir sobre diferentes tipos de superficies. $Y$, como se puede ver a continuación, un detallado análisis de las luces y sombras en un fotomontaje puede mostrar con facilidad si se trata de una imagen fraudulenta o no.

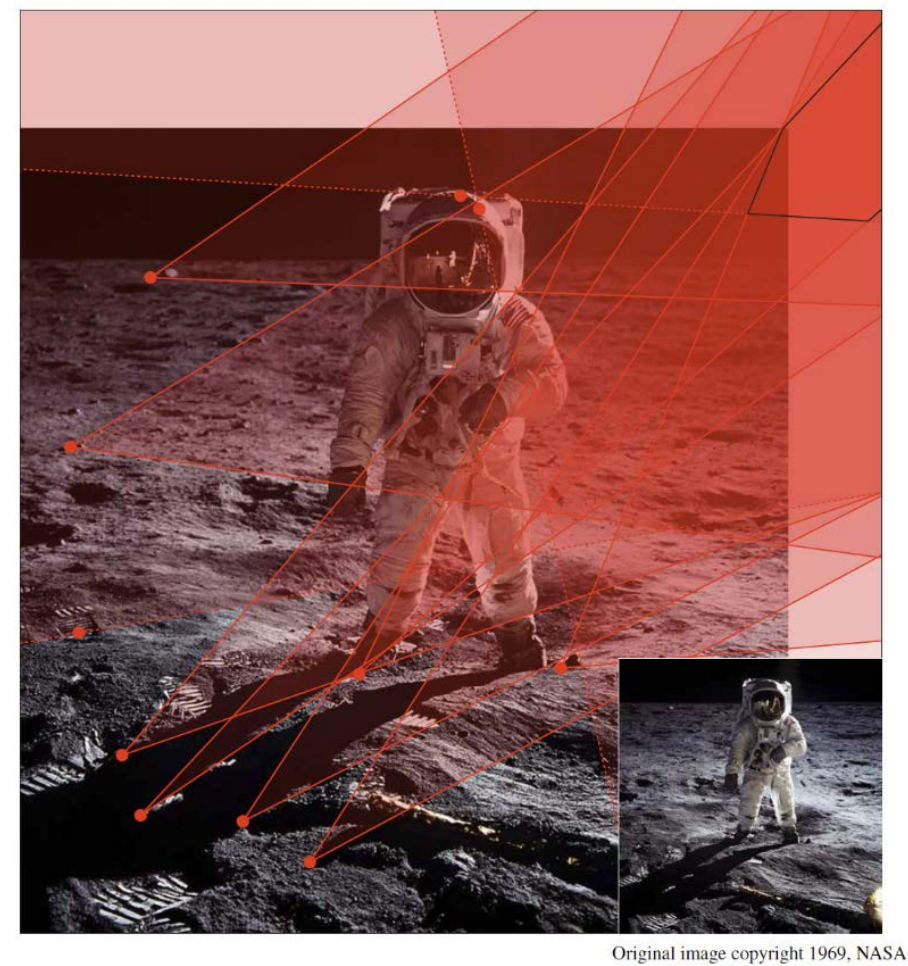

Figura 1: análisis de la imagen del alunizaje del Apolo XI en 1969 (Original de Kee, O'Brien \& Farid, 2013).

En palabras de los propios autores del estudio que desarrollaron un algoritmo específico para detección de la integridad de luces y sombras: "Our algorithm finds that the shadows in this 1969 moon landing photo are physically consistent with a single light source. The solid lines correspond to constraints from cast shadows and dashed lines correspond to constraints from attached shadows. The region outlined in black, which extends beyond 
the figure boundary, contains the projected light locations that satisfy all of these constraints" (Kee; O'Brien \& Farid, 2013).

El análisis no deja dudas, y la imagen de la llegada del hombre a la Luna que tomamos como ejemplo no es fraudulenta, y en consecuencia y a pesar de la persistencia de la especulación sobre su veracidad no hay debate alguno al respecto ${ }^{5}$ puesto que los resultados del análisis forense muestran una prueba más que suficiente de que la teoría conspirativa es falsa.

\section{Ejemplo 2. Manipulación de resultados de investigación.}

La mayoría de las técnicas de fotomontaje suelen utilizar un método que consiste en copiar un grupo de píxeles y repetirlo en otras zonas de la imagen. Es un método relativamente sencillo y si se hace con cierto cuidado se pueden realizar manipulaciones en la imagen difíciles de detectar a simple vista.

Las técnicas de detección de clonados y fotomontajes suelen ser también muy eficaces ya que se basan en la improbabilidad de que se repitan grupos de píxeles dentro de la misma imagen ${ }^{6}$ y se han desarrollado, en ese sentido, algoritmos para la identificación de zonas repetidas en una imagen o copiadas de otra de manera que, cómo se puede ver a continuación, se identifica con facilidad que la imagen ha sido manipulada.

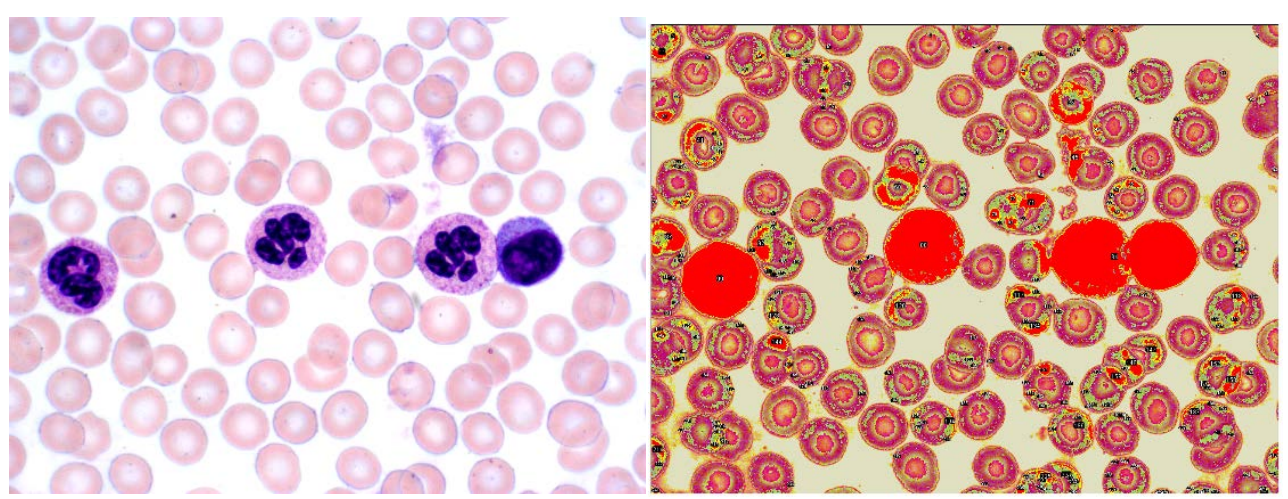

Figura 2: Análisis de manipulación de células clonadas

(Original de Alejandro Maestre Gasteazi).

En este caso el análisis ha detectado con claridad que la imagen se ha manipulado y, en consecuencia, en tanto se presenta como prueba fehaciente de los resultados de la investigación estos no pueden considerarse más que fraudulentos. Llegado el caso en que esta imagen tuviera que ser examinada por un tribunal, la certificación de validez llevada a cabo por un experto se convierte en una herramienta de inestimable valor.

\section{La práctica pericial.}

Una imagen digital que se quiera usar como prueba en un juicio o ser presentada en una publicación científica debe ser una evidencia que, en derecho procesal, se refiere la certeza clara, manifiesta y tan perceptible que nadie pueda dudar de ella (Pillado \& Canle, 2000)

\footnotetext{
5 Véase por ejemplo https://www.nationalgeographic.com.es/ciencia/actualidad/debate-interminable-pisohombre-luna_12999/1

${ }^{6}$ Un solo píxel de una imagen RGB de 8 bits es capaz de reproducir 16,7 millones de tonos diferentes por lo que una mínima matriz de $3 \times 3$ píxel puede llegar a reproducir $1,5 * 10^{60} \mathrm{combinaciones} \mathrm{posibles} \mathrm{y} \mathrm{la} \mathrm{probabilidad} \mathrm{de} \mathrm{que}$ se repita esa misma matriz en alguna otra parte de la imagen es prácticamente imposible.
} 
por lo que ha de ser: admisible, debiéndose ajustar a las normas legales que puedan ser presentadas ante un tribunal; auténtica, debe ser posible vincularla positivamente el material del incidente; completa, debe contar toda la historia y no sólo una particular perspectiva, indicando procedimiento, herramientas y aplicaciones utilizadas; confiable, se debe documentar cómo ha sido recogida describiendo la cadena de custodia ${ }^{7}$, cómo fue analizada, investigada y tratada; sin que arroje ninguna duda sobre su autenticidad y veracidad; $y$, finalmente, debe ser creíble, comprensible por un tribunal.

En este sentido y de la misma manera, aquellas imágenes que se quieren presentar como parte de una investigación científica deben conservar y adjuntar los archivos originales de tal forma que puedan demostrar su autenticidad como así lo recogen los códigos deontológicos y manuales de buenas prácticas en el tratamiento digital de imágenes científicas (Campa, 2017). Y, por supuesto, si se detecta que ha habido una falsificación puede derivar, cuanto menos, en la reprobación de la comunidad investigadora $y$, en muchos casos, en las acciones legales subsiguientes en función de la gravedad de los hechos y las consecuencias de la falsificación, por ejemplo, cuando la investigación se ha financiado con recursos públicos o privados o cuando las consecuencias del fraude pueden resultar en daños a terceros, etc.

Con las técnicas de análisis utilizadas en la peritación de imágenes científicas podemos comprobar la autenticidad o falsedad de cualquier imagen. Sin embargo, la mayoría de los algoritmos y herramientas de software se encuentran todavía en una fase teórica y experimental y no pueden evitar todavía un cierto nivel de falsos positivos de imágenes alteradas. Esto impide que los procesos de análisis se automaticen y puedan alcanzar los requisitos necesarios para utilizarse con garantías. Por ello, la labor del perito judicial sigue siendo hoy día imprescindible, teniendo que analizar caso por caso con una gran dedicación y rigor. Esta labor consume mucho tiempo para poder ofrecer las garantías que exigen los procedimientos judiciales. Es en estos procesos donde la elaboración de informes periciales adquiere cada vez más importancia pues permiten esclarecer tanto a los magistrados como a toda la comunidad científica la validez de imágenes de toda índole y que puedan ser objeto de fraude, entre ellas las científicas.

\section{Conclusiones.}

El fraude científico y la difusión de imágenes científicas falsas, tal como hemos visto a lo largo del texto tiene una larga tradición en la historia del conocimiento. Pero, sin duda, la incidencia que la falsificación está teniendo en la actividad científica en los últimos años y el potencial impacto que puede tener en lo sucesivo está movilizando a la comunidad científica ante un fenómeno complejo que es difícil atajar.

El análisis pericial de imágenes ofrece resultados esperanzadores para detener esta pandemia de falsificación tan indisociablemente ligada a la cultura visual contemporánea en que nos hallamos inmersos y que deriva de manera imparable hacia un intenso proceso de dataficación masiva sólo cognoscible mediante herramientas de representación visual del conocimiento (López-Cantos, 2017b). Sin embargo, necesita avanzar rápidamente

\footnotetext{
7 La cadena de custodia de una prueba se define como el procedimiento controlado que se aplica a los indicios materiales relacionados con el delito, desde su localización hasta su valoración por los encargados de su análisis, normalmente peritos, y que tiene por fin no viciar el manejo que de ellos se haga y así evitar alteraciones, sustituciones, contaminaciones o destrucciones.
} 
- Francisco López-Cantos, Alejandro Maestre Gasteazi

como disciplina científica para seguir dando respuesta a los requerimientos que se le plantean y responder con eficacia a los retos futuros. 


\section{Referencias bibliográficas}

11JIGEN (2012). Shigeaki Kato (the University of Tokyo): DNA demethylation in hormoneinduced transcriptional derepression. Recuperado de: http://katolabimagefraud.blogspot.co.uk/2012/01/dna-demethylation-in-hormone-induced.html

AGUADO, S. \& ANTONA, P.L. (2012). Aplicación de la técnica SVM en el análisis forense de imágenes de dispositivos móviles. Recuperado de: http://eprints.ucm.es/16102.

ALLEN, J. (1990). The Hubble Telescope - ODtid Failure Rewr (NASA-TM-103443). Recuperado de: https://www.ssl.berkeley.edu/ mlampton/AllenReportHST.pdf

BALMAS, M. (2012). When Fake News Becomes Real. Combined Exposure to Multiple News Sources and Political Attitudes of Inefficacy, Alienation, and Cynicism, Communication Research, 41 (3), pp. 430-454 DOI: 10.1177/0093650212453600

BECK, U. (1992). Risk Society, Towards a New Modernity. London: Sage Publications.

BROAD, W. \& WADE, N. (1982). Betrayers of the Truth. New York: Simon \& Schuster.

BUCCI, E. (2018). Automatic detection of image manipulations in the biomedical literature. Cell Death and Disease, 9 (400). DOI: 10.1038/541419-018-0430-3

CAMPA, V.M. (2017). Análisis de imágenes de microscopía con ImageJ. Ed. Createspace independiente.

CONOTTER, V., BOATO, G. \& FARID, H. (2010). Detecting photo manipulation on signs and billboards. Image Processing (ICIP), 2010 17th IEEE International Conference, 17411744. Recuperado de: http://ieeexplore.ieee.org/abstract/document/56529

COUZIN, J. (2006). Don't pretty up that picture just yet. Science, 314 (5807), 1866-1868. DOI: $10.1126 /$ science.314.5807.1866

CROMEY, D. W. (2013). Digital Images Are Data: And Should Be Treated as Such. Methods in Molecular Biology, 931, 1-27. DOI: 10.1007/978-1-62703-056-4_1

D'ANCONA, M. (2017). Post-truth:The new war on truth and how to fight back. London: Ebury Press.

DASTON, L. \& GALISON, P. (2007). Objectivity. Cambridge, Mass.: Zone Books.

FANELLI, D. (2009). How many scientists fabricate and falsify research? A systematic review and meta-analysis of survey data. PLoSOne. DOI: 10.1371/journal.pone.0005738

FARID, H. (2009). A 3-D Photo Forensic Analysis of the Lee Harvey Oswald Backyard Photo. Recuperado de: https://www.cs.dartmouth.edu/farid/downloads/publications/tr1o.pdf

FARID, H. (2019). Photoforensics. Massachusets: MIT Press. 
FROW, E. (2012). Drawing a Line: Setting Guidelines for Digital Image Processing in Scientific Journal Articles. Social Studies of Science, 42 (3), 369-392. DOI: $10.1177 / 0306312712444303$

GEST, H. (2009). Homage to Robert Hooke (1635-1703): New Insights from the Recently Discovered Hooke Folio. Perspectives in Biology and Medicine, 52 (2), 392-399. DOI: 10.1353/pbm.0.0096

GOODSTEIN, D. (1991). Engineering \& Science/Winter 1991. Recuperado de: https://core.ac.uk/download/pdf/46701765.pdf

HIGGINS, K. (2016). Post-truth: a guide for the perplexed. Nature, 540, 9. DOI: $10.1038 / 540009 a$

HUCKLE, S. \& WHITE, M. (2017). Fake News: A Technological Approach to Proving the Origins of Content, Using Blockchains. Big Data, 5 (4), 356-371. DOI: 10.108g/big.2017.0071

ITHENTICATE (2012). \$100 billion problem: Government duplicate spending. Recuperado de: https://www.ithenticate.com/hs-fs/hub/92785/file-16016813-pdf/docs/ithenticategov-grants-report.pdf

KEE, E., O'BRIEN, J.F. \& FARID, H. (2013). Exposing photo manipulation with inconsistent shadows. ACM Transactions on Graphics (ToG), 32 (3), 28.

KROLL, J. (2011). International Workshop on Accountability in Science and Research Funding. Recuperado de: https://www.nsf.gov/oig/_pdf/presentations/intl_workshops/brussels2011/13kroll.pdf

KRUEGER, J. (2009). Incidences of ORI cases involving falsified images. Office of Research Integrity Newsletter, 17(4), 2-3. Recuperado de: https://ori.hhs.gov/images/ddblock/sep_vol17_no4.pdf

KUCHARSKI, A. (2016). Study epidemiology of fake news. Nature, 540, 525. DOI: 10.1038/540525a

KUPFERSCHMIDT, K. (2018). Researcher at the center of an epic fraud remains an enigma to those who exposed him. Science. Recuperado de: https://www.sciencemag.org/news/2018/o8/researcher-center-epic-fraud-remainsenigma-those-who-exposed-him

LAZER, D. ET AL. (2018). The science of fake news. Science, 359 (6380), 1094-1096. DOI: 10.1126/science.aao2998

LOPEZ-CANTOS, F. (2010). La imagen científica: tecnología y arte $f$ facto. Revista Mediterranea de Comunicación, 1 (1), 158-172. DOI: 10.14198/MEDCOM2010.1.1.o9

LOPEZ-CANTOS, F. (2015). La simulación y representación de modelos y teorías científicas mediante imágenes. Thémata Revista de Filosofía, 51, 271-288. DOI: 10.12795/the $\neg$ mata. 2015.i51.14 
LOPEZ-CANTOS, F. (2016). Photography in the Boundaries of the Visible. From Santiago Ramón y Cajal to Cecil Frank Powell. Cogent Arts \& Humanities, 3 (1). DOI: 10.1080/233 11983.2016 .1182715

LOPEZ-CANTOS, F. (2017a). Comunicación pública de la ciencia y ética periodística. La representación del bosón de Higgs. Estudios sobre el mensaje periodístico, 23 (2), 11991213. DOI: 10.5209/ESMP. 58040

LOPEZ-CANTOS, F. (2017b). Cultura visual y conocimiento científico. Comunicación transmedia de la ciencia en la era Bigdata. Barcelona: UOC.

MARKOWITZ, D. M. \& HANCOCK, J. T. (2016). Linguistic Obfuscation in Fraudulent Science. Journal of Language and Social Psychology, 35 (4), 435-445. DOI: $10.1177 / 0261927 X_{15614605}$

MARMOT, M. (2017). Post-truth and science. The Lancet, 389 (10068), 497-498. DOI: 10.1016/S0140-6736(17)30207-6

MERTON, R. K. (1968). The Matthew Effect in Science. Science, 159 (3810), 56 63. DOI: $10.1126 /$ science.159.3810.56

MIHAILIDIS, P. \& VIOTTY, S. (2017). Spreadable Spectacle in Digital Culture: Civic Expression, Fake News, and the Role of Media Literacies in "Post-Fact" Society. American Behavioral Scientist, 61 (4), 441-454. DOI: 10.1177/0002764217701217

MISHRA, M. \& ADHIKARY, M.C. (2014). Detection of clones in digital images. Recuperado de: https://arxiv.org/abs/1407.6879.

NATURE (2006a) Not picture-perfect. Nature, 439, 891-892. DOI: 10.1038/439891b

NIGHTINGALE, S. J.; WADE, K. A. \& WATSON, D. G. (2017). Can people identify original and manipulated photos of real-world scenes? Cognitive Research: Principles and Implications, 2, 30. DOI: 10.1186/s41235-017-0067-2

NSF (2016). New Research Misconduct Policies. Recuperado de: https://www.nsf.gov/oig/_pdf/presentations/session.pdf

NUITJEN, M. ET AL. (2016). The prevalence of statistical reporting errors in psychology (1985-2013). Behavior Research Methods, 48 (4), 1205-1226. DOI: 10.3758/s13428-015$0664-2$

PARRISH, D. \& NOONAN, B. (2009). Image manipulation as research misconduct. Science and Engineering Ethics, 15 (2), 161-167. DOI: 10.1007/s11948-008-9108-z

PEARSON, H. (2005). CSI: Cell biology. Nature, 434, 952-953. DOI: 10.1038/434952a

PILLADO, E.G. \& CANLE, I.I. (2000). La prueba pericial en la nueva ley de enjuiciamiento Civil. Revista xurídica galega, 38. 
- Francisco López-Cantos, Alejandro Maestre Gasteazi

REYES, K. (2004). The post-truth era: Dishonesty and deception in contemporary life. New York: St. Martin's Press

SISMONDO, S. (2017). Post-truth? Social Studies of Science, 47 (1), 3-6. DOI: $10.1177 / 0306312717692076$

TANDOC, E. C.; LIM, Z. W. \& LING, R. (2018). Defining "Fake News". A typology of scholarly definitions. Digital Journalism, 6 (2), 137-153. DOI: 10.1080/21670811.2017.1360143

VARGO, C. J.; GUO, L. \& AMAZEEN, M. A. (2018). The agenda-setting power of fake news: A big data analysis of the online media landscape from 2014 to 2016. New Media \& Society, 20 (5), 2028-2049. DOI: 10.1177/1461444817712086 